\title{
Perubahan morfologi gigi permanen akibat bruksisma (Morphological changes of permanent teeth due to bruxism)
}

\author{
${ }^{1}$ Asmawati, ${ }^{2}$ Bahruddin Thalib, ${ }^{3}$ Rudin Tamril \\ ${ }^{1}$ Bagian Oral Biologi \\ ${ }^{2}$ Bagian Prostodonsia \\ ${ }^{3}$ Mahasiswa tahap profesi \\ Fakultas Kedokteran gigi Universitas Hasanuddin \\ Makassar, Indonesia
}

\begin{abstract}
Grinding or clenching teeth during sleep or unconsciously called bruxism. Bruxism is a bad habit that is occured in almost people, from children to adults. Bruxism closely related to changes in tooth morphology due to erosion of tooth surfaces, especially on the occlusal area. This study aimed to determine the morphological changes of permanent teeth due to bruxism. By using the method of observational analytic and cross-sectional design, the sample set in adults who experience bruxism as many as 69 samples; 23 samples do bruxism and 46 samples do not do bruxism. The results showed that the morphological changes on occlusal and incisal surfaces of the teeth in $78.3 \%$ of samples undergo bruxism, and samples do not undergo morphological changes as much as $21.7 \% .6 .5 \%$ of samples who did bruxism had dental morphology changes, and the prevalence is higher in men than women. With the chi-square test, it is known that there is significant effect $(p<0.05)$ of bruxism on morphological changes of permanent teeth. It was concluded that bruxism affect the morphological changes of permanent teeth.
\end{abstract}

Keywords: bruxism, morphological changes, permanent teeth

\begin{abstract}
ABSTRAK
Mengasah gigi atau mengatupkan gigi dengan keras baik pada saat tidur ataupun tidak sadar disebut dengan bruksisma. Bruksisma adalah suatu kebiasaan buruk yang hampir dilakukan semua orang, mulai dari anak-anak hingga dewasa. Bruksisma sangat erat hubungannya dengan perubahan morfologi gigi akibat erosi pada permukaan gigi, terutama pada daerah oklusal. Penelitian ini dimaksudkan untuk mengetahui perubahan morfologi gigi permanen akibat bruksisma. Dengan menggunakan metode observasi analitik dan rancangan cross sectional, ditetapkan sampel penelitian pada orang dewasa yang mengalami bruksisma sebanyak 69 sampel; 23 sampel dengan bruksisma dan 46 sampel tidak melakukan bruksisma. Hasil penelitian menunjukkan bahwa terjadi perubahan morfologi pada permukaan oklusal dan insisal gigi pada 78,3\% sampel yang bruksisma dan tidak mengalami perubahan morfologi sebanyak $21,7 \%$. Pada sampel yang tidak bruksisma, 6,5\% mengalami perubahan morfologi gigi, dan prevalensi lebih tinggi pada pria daripada wanita. Dengan uji chi-square, diketahui ada pengaruh yang signifikan $(\mathrm{p}<0,05)$ kejadian bruksisma pada perubahan morfologi gigi permanen. Disimpulkan bahwa bruksima berpengaruh pada perubahan morfologi gigi permanen
\end{abstract}

Kata kunci: bruksisma, perubahan morfologi, gigi permanen

Koresponden: Asmawati, E-mail: asmawatiamin68@yahoo.com

\section{PENDAHULUAN}

Kebiasaan buruk sangat berpengaruh terhadap bentuk dan antomi gigi-geligi. Salah satu kebiasaan buruk tersebut adalah bruksisma. ${ }^{1}$ Bruksisma sendiri merupakan suatu aktivitas dalam rongga mulut yang melibatkan sistem dan organ mastikasi, gigi-geligi, dengan melakukan gerakan mastikasi secara tidak sengaja dalam keadaan nonfunctional. Bruksisma dapat terjadi pada malam dan siang hari, pada saat tidur dalam keadaan sadar maupun tidak sadar.,

Faktor yang diduga menjadi penyebab bruksisma dibedakan menjadi faktor oklusal perifer dan faktor patopsikofisiologik sentral, diantaranya konsumsi alkohol, rokok, stres, pergantian waktu kerja, sakit kondisi medis, kelainan kejiwaan dan lain-lain. Pada waktu tidur, terjadinya bruksisma dapat dipengaruhi dan dikendalikan oleh pusat dan tingkat stres. Pola oklusi dapat mempengaruhi besarnya aktivitas otot selama terjadinya bruksisma. Sebenarnya bruksisma berfungsi melindungi manusia yaitu mengurangi efek stres psikis dan keadaan patologik., , $^{2,5}$

Bruksisma dapat mengubah secara perlahanlahan pada struktur rongga mulut, dimulai dari gigigeligi, gangguan sendi temporomandibula, hingga terjadi perubahan postur kepala, dan menyebabkan terkikisnya permukaan oklusal/insisal gigi karena adanya gesekan antar rahang, sehingga gigi terlihat mengalami kelainan bentuk dibanding gigi-gigi di sekitarnya. ${ }^{6}$

Bruksisma sering dikaitkan dengan anatomi gigi. Berdasarkan hasil riset ditunjukkan bahwa salah satu penyebab perubahan bentuk gigi adalah kebiasaan menggerindingkan gigi yang terjadi secara berulang atau tidak beraturan dapat menyebabkan keausan struktur gigi secara berkepanjangan sehingga gigi berubah bentuknya. ${ }^{2,7}$ 
Morfologi gigi terkait erat dengan karakteristik gigi-geligi, seperti tonjol yang terdapat pada gigi molar, premolar, dan kaninus biasanya berbentuk tonjolan padapermukaan oklusal dengan ukuran yang beraneka ragam. Apabila terjadi gesekan antara gigi rahang atas dan rahang bawah maka, tonjol-tonjol tersebut tidak jelas terlihat karena telah mengalami keausan. ${ }^{7}$

Permukaan oklusal/insisal dan tonjol-tonjol gigi merupakan indikator utama untuk menemukan tanda dan gejala bruksisma. Gesekan oklusal dan insisal antara gigi-geligi rahang atas dan rahang bawah akan berujung menjadi keausan yang selanjutnya dapat dijadikan untuk menentukan tingkat keparahan dari bruksisma. ${ }^{8,9}$

Penelitian ini dimaksudkan untuk mengetahui perubahan morfologi gigi geligi permanen akibat bruksisma.

\section{BAHAN DAN METODE}

Penelitian observasi analitik ini menggunakan rancangan penelitian desain cross-sectional dengan mengukur tingkat keparahan atrisi pada permukaan oklusal gigi posterior dan insisal gigi anterior. Sampel ditentukan dengan cara purposive sampling sehingga diperoleh jumlah 69 sampel, sebanyak 23 penderita bruksisma dan 46 tidak bruksisma.

Kriteria inklusi sampel penelitian yaitu penderita bruksisma yang berusia 17 tahun tahun ke atas dan sedang fase gigi permanen. Semua sampel menjawab pertanyaan kuisioner untuk mendeteksi bruksisma (American Academy of Sleep Medicine) yang berisi tentang kebiasaan dan gangguan yang berhubungan dengan adanya perubahan morfologi gigi, ${ }^{11}$ untuk memperoleh data penderita bruksisma, kemudian dilakukan pencetakan rahang sampel dan diukur keparahan atrisi dari gigi-geligi pada model studi.

Keparahan atrisi ditentukan berdasarkan beberapa dimensi yang diukur, yaitu adanya bruksisma, adanya atrisi, arah atrisi, bentuk atrisi, lokasi atrisi, dan derajat atrisi. Data tersebut lalu disesuaikan dengan Indeks Atrisi Gigi (Richards dan Brown) dengan skala 0 jika tidak ada atrisi/keausan dan tidak ada perubahan yang terjadi pada morfologi gigi akibat bruksisma,
1 jika keausan kecil, tonjol masih utuh dan perubahan belum terlihat jelas, 2 jika keausan terlihat sejajar dengan permukaan oklusal dan melibatkan kurang dari $1 / 3$ dentin dan sudah terjadi perubahan morfologi, 3 jika keausan pada tonjol atau groove dan melibatkan dentin lebih $1 / 3$ permukaan, dan perubahan bentuk sudah terlihat jelas, dan 4 jika keausan email sampai dentin sekunder hingga pulpa dan perubahan yang terjadi telah terlihat jelas. ${ }^{10}$

\section{HASIL}

Data pada tabel 1 menunjukkan jumlah sampel bruksisma dan tidak bruksisma. Sedangkan tabel 2 menunjuk kebiasaan yang dapat berpengaruh pada perubahan morfologi gigi. Berdasarkan kebiasaan tersebut, ditentukan responden yang menjawab "Ya" pada kebiasaan bruksisma dapat dijadikan sampel penelitian dan mungkin terjadi perubahan morfologi pada gigi-geliginya.

Tabel 1 Jumlah sampel bruksisma dan tidak bruksisma

\begin{tabular}{ccc}
\hline & $\mathrm{N}$ & $\%$ \\
\hline Bruksisma & 23 & 33,33 \\
Tidak Bruksisma & 46 & 66,67 \\
\hline Jumlah & 69 & 100 \\
\hline
\end{tabular}

Tabel 3 menunjukkan distribusikeparahan atrisi gigi berdasarkan adanya atrisi, serta sifat, bentuk, lokasi dan derajat atrisi gigi. Penilaian ini dilakukan berdasar pada foto intra oral penderita bruksisma, pemeriksaan keadaan gigi serta penilaian terhadap hasil cetakan model gigi.

Pada penilaian setiap dimensi, terlihat perbedaan yang sangat signifikan antarapenderita bruksisma dan bukan penderita bruksisma.Pada penderita bruksisma penilaian "adanya atrisi" yaitu semuanya mengalami atrisi pada gigi-geliginya sedangkan yang bukan penderita bruksisma juga mengalami atrisi namun tidak semua. Atrisi pada gigi-geligi yang dialami oleh penderita dan bukan penderita bruksisma mengalami karakteristik dan keparahan yang berbeda, yaitu lebih ditentukan oleh kebiasaan sehari-hari sehubungan dengan penggunaan gigi-geliginya, baik kebiasaan menyikat gigi, konsumsi makanan yang keras, dan lain sebagainya.

Tabel 2 Distribusi data kuisioner dan wawancara terstruktur kebiasaan sampel yang berhubungan dengan perubahan morfologi gigi

\begin{tabular}{ccccc}
\hline $\begin{array}{c}\text { Kebiasaan sampel yang } \\
\text { berhubungan dengan perubahan } \\
\text { morfologi gigi }\end{array}$ & Ya & Tidak & $\begin{array}{c}\text { Tidak } \\
\text { Tahu }\end{array}$ & Jumlah \\
\cline { 2 - 4 } & 17 & 52 & 0 & 69 \\
\hline Makan makanan yang keras & 7 & 62 & 0 & 69 \\
Menyikat gigi dengan keras & 1 & 68 & 0 & 69 \\
Pernah menggerinda gigi & 10 & 54 & 5 & 69 \\
Makan biji bijian & 23 & 30 & 16 & 69 \\
Bruksisma & & &
\end{tabular}


Penilaian karakteristik yang meliputi beberapa dimensi, seperti sifat atau arah atrisi, bentuk, dan lokasi atrisi.Pada dimensi "sifat atrisi" dari penderita bruksisma sebagian besar memiliki sifat atau arah 'datar' dan 'miring', sehingga terlihat dengan jelas perubahan yang terjadi pada permukaan atau tonjol dari gigi. Sedangkan pada dimensi "bentuk atrisi", penderita bruksisma memiliki bentuk yang 'tumpul', tapi ada yang 'tidak tampak bentuknya', tergantung dari keparahan atrisi yang terjadi. Untuk penilaian "lokasi atrisi" dari penderita bruksisma, paling sering terjadi pada 'daerah tonjol pendukung'. Hal ini terjadi karena daerah tersebut merupakan daerah yang paling sering berkontak dengan gigi antagonisnya; selain itu daerah tempat terdapatnya keausan, yaitu daerah 'persentuhan sisi kerja' yang telah melibatkan semua permukaan gigi yang bersentuhan maupun yang tidak bersentuhan secara langsung dengan gigi antagonis, dan ada juga yang tidak tampak daerah atau lokasi terdapatnya atrisi. 'Derajat keparahan atrisi gigi' dapat ditentukan berdasarkanjaringan gigi yang mengalami kehilangan. Berdasarkan penilaian yang dilakukan pada atrisi yang terjadi lebih banyak yang mengalami 'atrisi email dengan dentin terbuka' selanjutnya 'atrisi dengan dentin terlihat dengan keadaan ringan pada permukaan oklusal dan insisal' dan atrisi ringan yaitu atrisi email sangat minimal dengan tonjol yang masih utuh dengan frekuensi rendah.

Penilaian morfologi untuk menentukan terjadi perubahan atau tidak, dapat ditentukan dari penilaian atrisi tersebut. Pada penilaian 'tidak ada atrisi dan atrisi kecil dengan tonjol masih utuh', menunjukan belum terjadi perubahan. Sedangkan pada penilaian 'atrisi sejajarpermukaan, atrisi tonjol dan grooveyang melibatkan dentin, danatrisiyang email hingga pulpa' menunjukkan telah terjadi perubahan morfologi.

Tabel 4 menunjukan distribusi perubahan bentuk morfologi gigi permanen oleh kebiasaan bruksisma berdasarkan penilaian atrisi dengan menggunakan indeks atrisi gigi, menunjukan sampel bruksisma sebagian besar mengalami perubahan bentuk pada gigi, dan hanya sebagian kecil yang tidak mengalami

Tabel 3 Distribusi penilaian hasil Model studi yang mengalami atrisi karena bruksisma berdasarkan dimensi adanya atrisi, sifat, bentuk, lokasi dan derajat atrisi gigi

\begin{tabular}{|c|c|c|c|c|c|c|c|c|c|c|}
\hline \multirow{3}{*}{ Dimensi Atrisi Gigi } & \multicolumn{10}{|c|}{ Sampel Penderita Bruksisma } \\
\hline & \multicolumn{2}{|c|}{ Jumlah Penderita } & \multicolumn{6}{|c|}{ Penilaian (Skor) } & \multicolumn{2}{|c|}{ Perubahan } \\
\hline & $\mathrm{n}$ & $\%$ & 0 & 1 & 2 & 3 & 4 & 5 & Ada & Tidak \\
\hline \multicolumn{11}{|l|}{ Adanya atrisi } \\
\hline 1 Ada Atrisi & 23 & 100 & & & $\sqrt{ }$ & & & & $\sqrt{ }$ & $\sqrt{ }$ \\
\hline \multicolumn{11}{|l|}{ Sifat Atrisi } \\
\hline 1 Tidak tampak arah atrisi & 5 & 21,74 & & $\sqrt{ }$ & & & & & & $\sqrt{ }$ \\
\hline 2 Arah miring & 14 & 60,87 & & & $\sqrt{ }$ & & & & $\sqrt{ }$ & \\
\hline 3 Arah datar & 4 & 17,39 & & & & $\sqrt{ }$ & & & $\sqrt{ }$ & \\
\hline 4 Arah membulat & 0 & 0 & & & & & & & & \\
\hline 5 Gabungan arah & 0 & 0 & & & & & & & & \\
\hline \multicolumn{11}{|l|}{ Bentuk Atrisi } \\
\hline 1 Tidak tampak bentuk atrisi & 11 & 47,83 & & $\sqrt{ }$ & & & & & $\sqrt{ }$ & \\
\hline 2 Tumpul & 12 & 52,17 & & & $\sqrt{ }$ & & & & $\sqrt{ }$ & \\
\hline 3 Bentuk faset & 0 & 0 & & & & & & & $\sqrt{ }$ & \\
\hline \multicolumn{11}{|l|}{ Lokasi atrisi } \\
\hline 1 Tidak tampak lokasi atrisi & 6 & 26,09 & & $\sqrt{ }$ & & & & & & $\sqrt{ }$ \\
\hline 2 Daerah tonjol pendukung & 14 & 60,87 & & & $\sqrt{ }$ & & & & $\sqrt{ }$ & \\
\hline 3 Daerah Persentuhan sisi kerja & 3 & 13,04 & & & & & & & $\sqrt{ }$ & \\
\hline \multicolumn{11}{|l|}{ Derajat atrisi } \\
\hline 1 tidak ada atrisi & 0 & 0 & & & & & & & & \\
\hline 2 atrisi email sedikit tapi tonjol masih utuh & 5 & 21,74 & & & $\sqrt{ }$ & & & & & $\sqrt{ }$ \\
\hline $\begin{array}{l}3 \text { atrisi email dengan dentin terbuka (gigi tampak } \\
\text { berwarna kuning) }\end{array}$ & 10 & 43,48 & & & & $\sqrt{ }$ & & & $\sqrt{ }$ & \\
\hline 4 dentin terlihat, mulai dari ringan sampai berat & 8 & 34,78 & & & & & $\sqrt{ }$ & & $\sqrt{ }$ & \\
\hline TOTAL & & & & Sam & apel & $(10$ & $0 \%)$ & & & \\
\hline
\end{tabular}

Tabel 4 Distribusi perubahan morfologi gigi permanen berdasarkan kebiasaan bruksisma

\begin{tabular}{|c|c|c|c|}
\hline \multirow[b]{2}{*}{ Kebiasaan buruk } & \multicolumn{2}{|c|}{ Perubahan } & \multirow{2}{*}{ Total } \\
\hline & Ada Perubahan & Tidak Ada Perubahan & \\
\hline Bruksisma & $18(78,3 \%)$ & $5(21,7 \%)$ & $23(100 \%)$ \\
\hline Tidak Bruksisma & $3(6,5 \%)$ & $43(93,5 \%)$ & $46(100 \%)$ \\
\hline Total & $21(30,4 \%)$ & $48(69,6 \%)$ & $69(100 \%)$ \\
\hline
\end{tabular}


perubahan bentuk. Analisis perubahan morfologi gigi akibatbruksisma denganujichi-square dengan Fisher exact test dengan hasil $\mathrm{p}=0,0005$ yang mengindikasi adanya pengaruh yang signifikan antara bruksisma dengan perubahan bentuk gigi permanen $(p<0,05)$.

\section{PEMBAHASAN}

Jumlah Sampel pada penelitian ini terdiri dari 23 orang penderita bruksisma, 46 orang bukan penderita bruksisma dijadikan sebagai pembanding, sehingga total sampel 69 orang yang terlihat pada tabel 1 .

Perubahan morfologi gigi dalam penelitian ini diketahui dengan melakukan pemeriksaan pada gigi geligi, dan penilaian atrisi pada hasil cetakan rahang sampel penderita bruksisma,kemudian dibandingkan dengan bukan penderita bruksisma. Untuk menilai keadaan atrisi gigi-geligi disebabkan oleh bruksisma atau penyebab lain, maka dilakukan screening atau wawancara terstruktur mengenai kebiasaan sampel yang berhubungan penyebab terjadinya perubahan bentuk gigi-geligi. Pada tabel 2 disajikan distribusi hasil wawancara terstruktur mengenai kebiasaan sampel.

Berdasarkan penelitian yang dilakukan pada 23 penderita bruksisma, tampakbahwa semua penderita bruksisma mengalami atrisi pada gigi-geliginya. Pada penilaian atrisiberdasarkan sifatnya, terdapat $21,74 \%$ sampel tidak tampak arah atrisinya, $60,87 \%$ sampel arah atrisinya miring, sedangkan arah datar memiliki frekuensi paling sedikit, yaitu 17,39\%. Pada penilaian bentuk atrisi terdapat tiga kategori, yaitu atrisi yang bentuknya tidak tampak $(47,83 \%)$, bentuk atrisi yang tumpul $(52,17 \%)$, dan bentuk faset tidak ditemukan dalam penelitian ini. Lokasi atrisi paling banyak di daerah tonjol $(60,87 \%)$. Sedangkan penilaian atrisi berdasarkan derajat atrisi, frekuensinya paling banyak terjadi atrisi email yang melibatkan dentin sehingga gigi tampak berwarna kekuningan; yaitu 43,48\% dari sampel penelitian.

Dalam menentukan perubahan bentuk dilakukan dengan membandingkan ukuran atau bentuk gigi seperti keadaan permukaan atau tonjol gigi. Pada permukaan gigi yang dapat dilihat seperti panjang tonjol dengan membandingkan dengan tonjol-tonjol gigi sekitarnya dan ketajamannya. ${ }^{9}$

Ditinjauberdasarkanjenis kelamin, laki-lakipada penelitian ini lebih banyak mengalami atrisi pada gigi-geliginya dibanding perempuan sehingga lakilaki memiliki kemungkinan lebih banyak mengalami perubahan morfologi pada gigi-geliginya.

Ditinjau berdasarkan usia penderita bruksisma pada peneltian ini, tidak dapat disimpulkan bahwa usia memiliki pengaruh karena jumlah sampel yang tidak merata pada setiap kelompok usia.
Pernyataan Khan, dkk yang mengutip Unggar dan Williamson, ditegaskan bahwa bentuk, tinggi tonjol dan cekungan-cekungan yang terdapat pada permukaan oklusal dan insisal sangat informatif dalam menentukan perubahan fungsi dan morfologi terhadap pada gigi geligi. ${ }^{9}$

Pada penilaian dimensi 'adanya atrisi' sangat menentukan apakah telah terjadi perubahan pada gigi geligi. Adanya atrisi gigi merupakan hal yang palingutama mengawali terjadinya perubahan bentuk gigi geligi, kemudian ditentukan oleh sifat, bentuk, lokasi dan derajat keparah dari atrisi gigi tersebut.

Secara klinis, karakteristik gigi merupakan tanda pertama untuk menentukan keberadaan bruksisma, dengan mengetahui morfologi yang normal terutama permukaan oklusal, tonjol maupun kedalaman fisur. Dari aspek jenis kelamin, penderita bruksisma tidak memperlihatkan perbedaan yang signifikan, hanya dipengaruhi kebiasaan rutin penderita tersebut. Jadi jenis kelamin tidak berpengaruh terhadap terjadinya bruksisma dan perubahan bentuk gigi permanen. ${ }^{13}$

Adanya kebiasaan buruk seperti makan makanan yang keras, makan biji-bijian dan menggerinding gigi dapatmenyebabkan terjadinya perubahan morfologi pada gigi-geligi.Namun pada penelitian iniperubahan yang disebabkan oleh kebiasaan tersebut diabaikan, sehingga penyebab yang diamati hanya perubahan yang disebabkan oleh bruksisma.

Indikator perubahan morfologi gigi-geligi dalam kaitannya dengan kebiasaan buruk saat tidur, yaitu bruksisma, menggunakan pengukuran atau penilaian seberapa besar atrisi yang dialami oleh gigi tersebut yang mempengaruhi bentuk/morfologinya. Peneliti sebelumnya, yaitu Glinka dkk, menggunakan kriteria derajat atrisi dan indeks atrisi menurut Richards dan Brown dalam menentukan keparahan dan hubungan atrisi dengan morfologi gigi geligi. ${ }^{12}$

Glinka, dkk yang dikutp oleh Krisnowati yang menyatakan bahwa keparahan atrisi digolongkan berdasarkan derajat keparahannya, sifat, bentuk, dan lokasi atrisi, kemudian diaplikasikan dalam indeks atrisi sehingga memudahkan menentukan ada atau tidaknya perubahan yang terjadi pada bentuknya. ${ }^{11}$

Menurut Richards dan Brown, untukmenentukan penilaian terhadap atrisi gigi dapat digunakan indeks atrisi.Pada indeks atrisi subjek penilaian terdiri dari, tidak adanya atrisi, atrisi yang minimal pada email, atrisi yang terlihat sejajar dengan permukaan oklusal dan melibatkan $1 / 3$ dentin, keausan pada tonjol dan groove dan melibatkan lebih dari $1 / 3$ dari dentin, serta kehilangan total kontur yang melibatkan pulpa. ${ }^{12}$

Dari penelitian ini, disimpulkan bahwa bruksisma berpengaruh signifikan terhadap perubahan bentuk gigi permanen dibandingkan dengantidak bruksisma. 


\section{DAFTAR PUSTAKA}

1. Muhamad HA, Hendrastuti H, Fajriani F. Kebiasaan buruk (bad habit) pada anak: buku ajar maloklusi pada anak. Makassar: Penerbit Bimer Makassar; 2012. pp.240

2. Wendari AH, Nunung R, Aprilia A. Bruksisma. J Dentofasial 2011; 10 (3): 135

3. Basic V, Mehulic K. Bruxisma: an unsolved problem in dental medicine. Acta Stomatol Croat 2004; 38:1

4. Ciancaglini R, Enrico FG, Radaelli G. The relationship of bruxism with craniofacial and simptoms from the masticatory system in the adult population. J Oral Rehabil 2001; 28: 842-8

5. Wijaya Y, Laura SH, Roselani WO. Occlusal grinding patern during sleep bruxism and temporomandibular disorder. J Dent Indonesia 2012; 20(2): 25-31

6. Tanzil A. Peran oral splin pada bruxisme. Indonesian J Dent 2008; 15: 36-43

7. Paesani AD, editor. Bruxism: theory and practice. London: Quintesence Publishing. pp.3-22

8. Myrtaty A. Variasi non-metris pada geligi manusia. Surabaya: Departemen Antropologi FISIP Unair; 2008

9. Khan F, Young WG, Daley TJ. Dental erosion and bruxism: a tooth wear analysis from South East Queensland. Aust Dent J 1998; 43

10. Evans, Alistair R. Connecting morphology, function and tooth wear in microchiropterans. Biol J Linnean Soc 2005; 85: 81-96

11. Krisnowati. Perubahan morfologi oklusal dan insisal gigi permanen sebagai gejala diagnosis. Surabaya: Pustaka Hang Tuah Pekan Baru; 2000. hal. 4-6

12. Litonjua LA, Sebastian A, Bush PJ. Tooth wear: atrition, erition and abrasion. J Res Dent 2003; 34(6).

13. Luis J. Sleep bruxism conceptual review and update. journal section: Orofacial Pain-TMJD 2001; 16(2) 